OECDpublishing

\title{
THE IMPACT OF THE AFRICAN SWINE FEVER OUTBREAK IN CHINA ON GLOBAL AGRICULTURAL MARKETS
}

OECD FOOD, AGRICULTURE AND FISHERIES PAPER

May $2021 \mathbf{n}^{\circ} \mathbf{1 5 6}$ 


\title{
OECD TRADE AND AGRICULTURE DIRECTORATE
}

\section{The Impact of the African Swine Fever Outbreak in China on Global Agricultural Markets}

\author{
Clara Frezal, Stephan Hubertus Gay, Claude Nenert
}

In China, the outbreak of the African Swine Fever is expected to result in a $27 \%$ drop in the production of pigmeat, the country's most consumed meat product. Using the OECD-FAO Aglink-Cosimo model, this paper examines the impact of this production shortfall on global markets for livestock products and animal feed over the short and the medium term. In particular, it compares outcomes if the changes induced by the ASF outbreak in China are temporary with outcomes that could result if current changes lead to a restructuring of Chinese protein demand.

Keywords: Pigmeat, pandemic, agricultural trade, feed market

JEL codes: C61, F17, Q11, Q17

\section{Acknowledgements}

The authors are grateful to Canada for the Voluntary Contribution, to Lee Ann Jackson, Annelies Deuss, Céline Giner and Grégoire Tallard (OECD) for their review and valuable comments, and to Michèle Patterson for preparing this report for publication. The authors also wish to thank the members of the OECD Joint Working Party on Agriculture and Trade for their valuable comments and direction. 


\section{Table of contents}

1. What's the issue? 3

2. Description of the ASF scenarios $\quad 5$

$\begin{array}{ll}\text { 3. Results } & 6\end{array}$

$\begin{array}{lr}\text { 4. Conclusion } & 13\end{array}$

$\begin{array}{lr}\text { References } & 14\end{array}$

\section{Figures}

Figure 1. Evolution of pigmeat prices in China, Germany, Brazil, and the United States 5

Figure 2. Chinese pigmeat output falls by $27 \%$ below levels foreseen without ASF in the short term 7

Figure 3. Pigmeat consumption falls, benefiting other livestock products 8

Figure 4. Production drop causes a short-term rise in Chinese pigmeat imports 9

Figure 5. ASF outbreak in China creates temporary export opportunities for the European Union,
the United States, Brazil, and Canada

Figure 6. ASF supports global pigmeat prices 11

Figure 7. ASF outbreak reduces feed use in China $\quad 12$

Figure 8. ASF temporarily reduces Chinese imports of soybean and feed grains 13 


\section{Key messages}

- The 27\% drop in Chinese pigmeat production due to the outbreak of African Swine Fever (ASF) is mainly found to have short-term impacts on global agricultural markets given the anticipated quick recovery in Chinese production.

- Short-term impacts include a $15 \%$ reduction in pigmeat consumption in China, and an increase in consumption of other livestock products (eggs, poultry and fish in particular) as these become more affordable or simply more available. In addition, Chinese pigmeat imports are expected to increase by $2.6 \mathrm{Mt}$ above levels foreseen in the absence of ASF in order to meet domestic demand, creating temporary export opportunities for countries unaffected by ASF.

- High Chinese import demand causes an increase in international pigmeat prices. In the short term, international prices increase by almost $9 \%$ above levels foreseen in the absence of ASF, but from a low base as COVID-19 has been placing downward pressure on livestock prices.

- The shock on Chinese pigmeat output is found to spill over into the feed market, causing a $50 \mathrm{Mt}$ reduction in Chinese feed use and a $5.5 \mathrm{Mt}$ reduction in Chinese imports of maize, soybean and other coarse grains, the main components of hog rations.

- As Chinese pigmeat output starts recovering, however, pigmeat consumption, trade and prices, as well as feed use and imports, are expected to gradually approach levels foreseen in the absence of ASF in the medium term.

- If the shock from ASF induces a permanent restructuring of Chinese protein demand, then the medium-term effects of ASF on global agricultural markets could be significant. A more permanent $8 \%$ shift in Chinese demand away from pigmeat towards less feed-intensive livestock products could reduce feed use in China by $8 \mathrm{Mt}$ per year in the medium term.

- The projections in this paper are subject to a number of uncertainties. These relate to the recovery path of China and other countries affected by ASF; to the spread of ASF to other countries; the pace of recovery from the COVID-19 pandemic; and the trade tensions and restrictions in the pigmeat and feed markets.

\section{What's the issue?}

In August 2018, the Ministry of Agriculture and Rural Affairs (MARA) of the People's Republic of China (hereafter "China") confirmed its first African Swine Fever (ASF) outbreak. China, the world's largest pigmeat market, accounts for about $45 \%$ of global production and consumption. Its pigmeat output fell by more than $20 \%$ in 2019. Further reductions in production occurred in the first three quarters of 2020, leading to a surge in domestic prices (Box 1).

As pigmeat is the principle source of animal protein in China, this shortfall in domestic production affects global agricultural markets. ${ }^{1}$ Going forward, the impacts of the production shock on pigmeat could continue to reverberate on markets for other livestock products and have lingering effects on feed markets should consumers shift to other protein sources on a more permanent basis.

\footnotetext{
${ }^{1}$ In 2017 , pigmeat accounted for $60 \%$ of total meat protein consumption and $32 \%$ of total animal protein consumption in China, according to the OECD-FAO Agricultural Outlook 2020-2029 (OECD/FAO, 2020[12]).
} 
This paper examines these global impacts over the short and the medium term using the Aglink-Cosimo model. ${ }^{2}$ In particular, it compares outcomes if the changes induced by the ASF outbreak in China are temporary with outcomes that could result if current changes lead to a restructuring of Chinese protein demand.

\section{Box 1. Background on ASF}

\section{What is ASF?}

African Swine Fever (ASF) is a highly contagious viral disease affecting domestic and wild pigs. It does not affect humans or other species. Symptoms include fever, loss of appetite, lack of energy, miscarriages, and internal bleeding. Severe strains of the virus are generally fatal.

ASF is responsible for serious economic and production losses in the pigmeat sector due to its high mortality rate and the trade restrictions imposed on affected countries.

\section{Transmission and spread}

Healthy pigs and wild boar usually become infected through:

- direct contact with an infected animal

- indirect contact with an infected animal, i.e. ingestion of contaminated materials such as food waste, feed, or garbage, and

- bites by infectious ticks.

\section{Prevention and control}

There are no approved vaccines or cures for ASF.

Prevention in countries free of the disease mainly consists of import policies and biosecurity measures to prevent infected live pigs or pigmeat products from entering the territory.

Control measures in affected countries include humane killing of animals (with proper disposal of carcasses and waste), thorough cleansing and disinfection, zoning and movement controls, surveillance and detailed epidemiological investigation, and strict biosecurity measures on farms.

Effective management of the wild boar population is required to successfully prevent and control ASF.

\section{Geographical distribution}

ASF has been infecting wild boar from Sub-Saharan Africa for at least a century and the disease has become endemic in this region. The first cases outside Africa date back to the 1960 s and are linked to the development of international trade. At the time, the disease spread to the Americas and Europe, but was eradicated fairly rapidly.

In 2007, however, Europe was once again affected, with initial detection of ASF in Georgia. ASF then spread to Eurasia (Armenia, Azerbaijan, and southern Russia), eventually reaching Belarus.

In 2014, ASF was detected in the European Union, initially in Poland and the Baltic States. The disease has since continued to spread; as of April 2021, it was present in seven Member States, including Germany, the largest European pigmeat producer and the world's third largest pigmeat exporter. Since Germany recorded its first cases of ASF in September 2020 its pigmeat exports outside the European Union have dropped, putting downward pressure on domestic prices (Figure 1). ${ }^{1}$

\footnotetext{
2 Aglink-Cosimo is a comprehensive partial equilibrium model for global agriculture. It underlies the baseline projections of the OECD-FAO Agricultural Outlook 2020-2029 (OECD/FAO, 2020[12]). A detailed documentation on the Aglink-Cosimo model is available at http://www.agri-outlook.org/about/.
} 
In addition, since August 2018, when ASF was first detected in China, the Asian continent has been widely affected. The disease spread to Mongolia, Taiwan, Viet Nam, Cambodia, the Democratic People's Republic of Korea, the Lao People's Democratic Republic, Myanmar, the Philippines, Korea, Timor-Leste and Indonesia in 2019, to India in 2020, and to Malaysia in 2021. As of August 2019, almost 5 millions pigs had died or been culled in Asia because of the spread of ASF.

\section{Figure 1. Evolution of pigmeat prices in China, Germany, Brazil, and the United States}

March 2017-March 2021

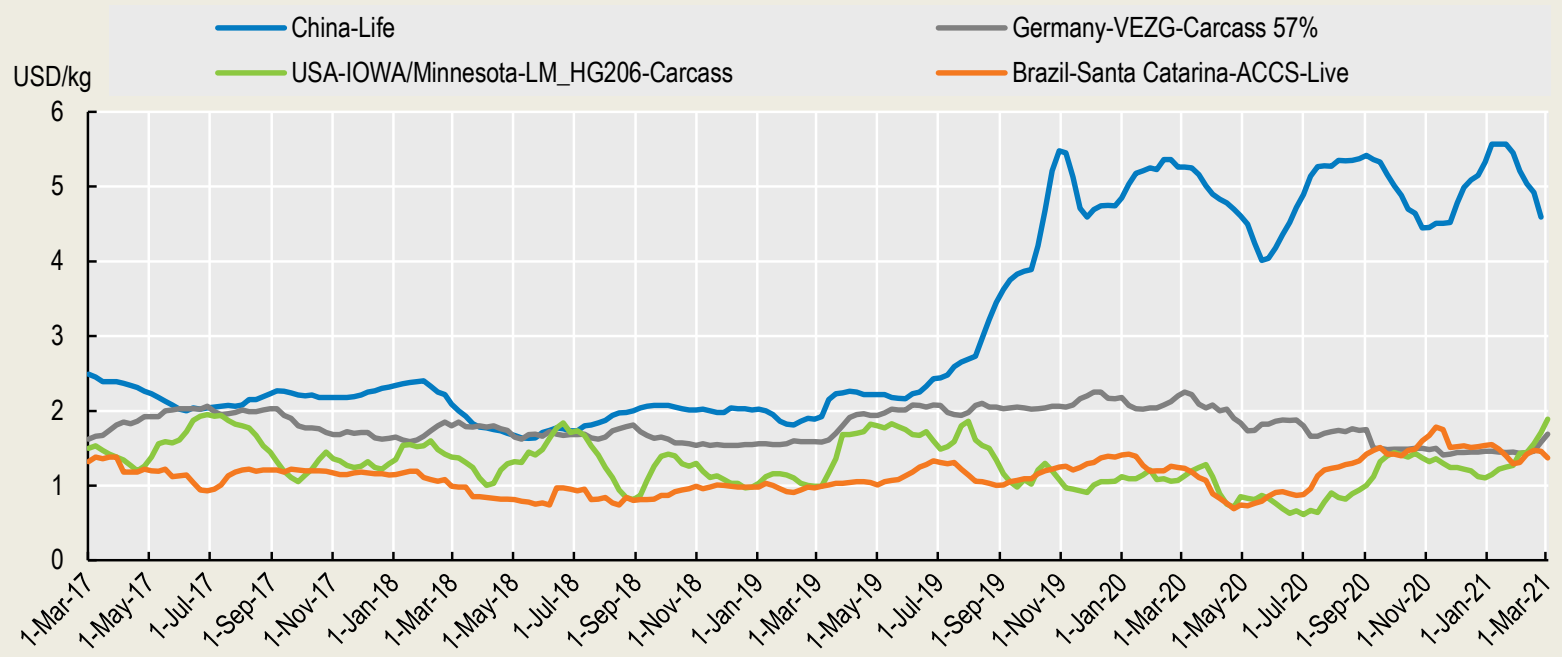

Source: (pig333.com, 2021 [1]).

1. A number of countries have put bans on German pigmeat exports, including China, Germany's largest export market. The impact of the ASF outbreak in Germany is not included here.

Sources: (European Food Safety Authority, n.d.[2]) (World Organisation for Animal Health, 2018[3]) (anses, 2021 $\left.{ }_{[4]}\right)\left(\right.$ FAO, 2021 $\left.{ }_{[5]}\right)$ (European Commission, 2021[6]) $($ FAO, 2021[7]).

\section{Description of the ASF scenarios}

The present paper considers three pathways for the evolution of pigmeat production in China. These scenarios use the baseline of the OECD-FAO Agricultural Outlook 2020-2029, and include the macroeconomic and other impacts of the global COVID-19 pandemic on agricultural markets. ${ }^{3}$ Building on the baseline, each scenario makes different assumptions regarding the evolution of Chinese pigmeat production. Specifically, the following three scenarios are considered:

\footnotetext{
3 The macroeconomic assumptions underlying the baseline are based on the OECD Economic Outlook, published in December 2020, and on the IMF World Economic Outlook from October 2020. The OECD projects that after a $4.2 \%$ decline in 2020 , global GDP will rise by $4.25 \%$ in 2021 , and by a further $3.75 \%$ in 2022 . The IMF projects a $4.4 \%$ drop in global GDP in 2020, followed by a $5.4 \%$ recovery in 2021 . Other assumptions include short-term increases in the producer-consumer price margin and in trade costs. For more details about these assumptions and in depth analysis of the impact of the COVID-19 pandemic on agricultural commodity markets, please refer to OECD (2020[11]).
} 
no_ASF

This counterfactual scenario assumes no ASF in China and Viet Nam in 2019 and for the rest of the projection period (i.e. from 2020 to 2029). It uses data on pigmeat production in China and Viet Nam from the 2019 edition of the OECD-FAO Agricultural Outlook, which does not include the impact from ASF (OECD/FAO, 2019[8]).

\section{temporary_ASF}

This scenario assumes a temporary shock on Chinese pigmeat production. It uses data from the United States Department of Agriculture (USDA) from October 2020 for pigmeat production in China in 2020 and 2021 (USDA, 2020[9]). The USDA projects that Chinese pigmeat output will drop by a further $10.7 \%$ in 2020 (as compared to the production in 2019) before increasing by $8 \%$ in 2021. After 2021, Chinese pigmeat production is expected to continue its recovery based on the assumption that China will control the disease, but to remain 2.5\% below no_ASF level by 2029.

\section{structural_ASF}

This scenario assumes a structural shock on Chinese protein demand. In addition to the temporary shock on pigmeat production in 2020-21 included in the temporary_ASF scenario, this scenario assumes a restructuring of Chinese protein demand following a change in consumer preferences. Specifically, after 2021 and until 2029, it assumes that Chinese pigmeat demand falls by $8 \%$ below the levels of demand foreseen in the absence of ASF, and that this lower demand for pigmeat is replaced by increasing demand for other livestock products ( $50 \%$ by poultry, $25 \%$ by fish, and $25 \%$ by eggs). ${ }^{45}$ This shock on Chinese pigmeat demand results in a slower recovery of Chinese pigmeat production after 2021, keeping pigmeat output 10\% below no_ASF levels, on average, between 2022 and 2029.

This paper looks at the short- and medium-term impacts of the ASF outbreak in China on global agricultural markets by comparing outcomes under the two ASF scenarios (temporary_ASF and structural_ASF) with outcomes under the counterfactual scenario in which no ASF has occurred (no_ASF). All the results are simulated, based on the latest official commodity balances for pigmeat, which are those of the calendar year $2019 .{ }^{6}$ In this paper, short term refers to the average of the years 2020 and 2021, and medium term refers to the end of the projection period (i.e. 2029).

\section{Results}

In the short term, under both the temporary_ASF and structural_ASF scenarios, pigmeat production in China is projected to be $27 \%$ below the production levels foreseen without ASF. Thereafter, pigmeat output is expected to gradually recover under these scenarios but to remain $2.5 \%$ and $6 \%$ below no_ASF levels, respectively, by the end of the projection period (Figure 2). The speed of recovery from ASF largely depends on the measures taken by China to contain the spread of the disease and to rebuild supply. Various measures have been introduced by the government since 2019, including subsidies for culling herds, increased financial support for the development of large-scale production facilities that can ensure biosecurity, and scientific research to develop a vaccine. However, uncertainty remains around the recovery path from ASF. New strains of ASF recently discovered in China pose new challenges for the

\footnotetext{
4 This breakdown is based on developments in animal protein consumption in China. In recent years, poultry consumption has experienced the fastest growth among livestock products. As poultry is also considered as the closest substitute to pigmeat, we assumed that it picks up 50\% of the drop in pigmeat consumption. Fish and eggs, which also account for a large share of animal protein consumption, are assumed to pick up the remaining $50 \%$. Ruminant meats contribute to only $10 \%$ of animal protein consumption in China. We therefore assumed that it do not benefit from the reduction in pigmeat demand.

${ }^{5}$ Despite the temporary shock on Chinese production and the structural shock on protein demand, in 2029, per capita pigmeat consumption under ASF_structural is projected to be $5 \%$ above 2018 level.

${ }^{6}$ At present, only preliminary data are available for the year 2020.
} 
control of the disease and could prevent a quick recovery in Chinese production in the absence of an effective vaccine (FAO, 2021 $\left.{ }_{[5]}\right)$.

\section{Figure 2. Chinese pigmeat output falls by $27 \%$ below levels foreseen without ASF in the short term}

Chinese pigmeat production under no_ASF, temporary_ASF and structural_ASF, 2018-2029

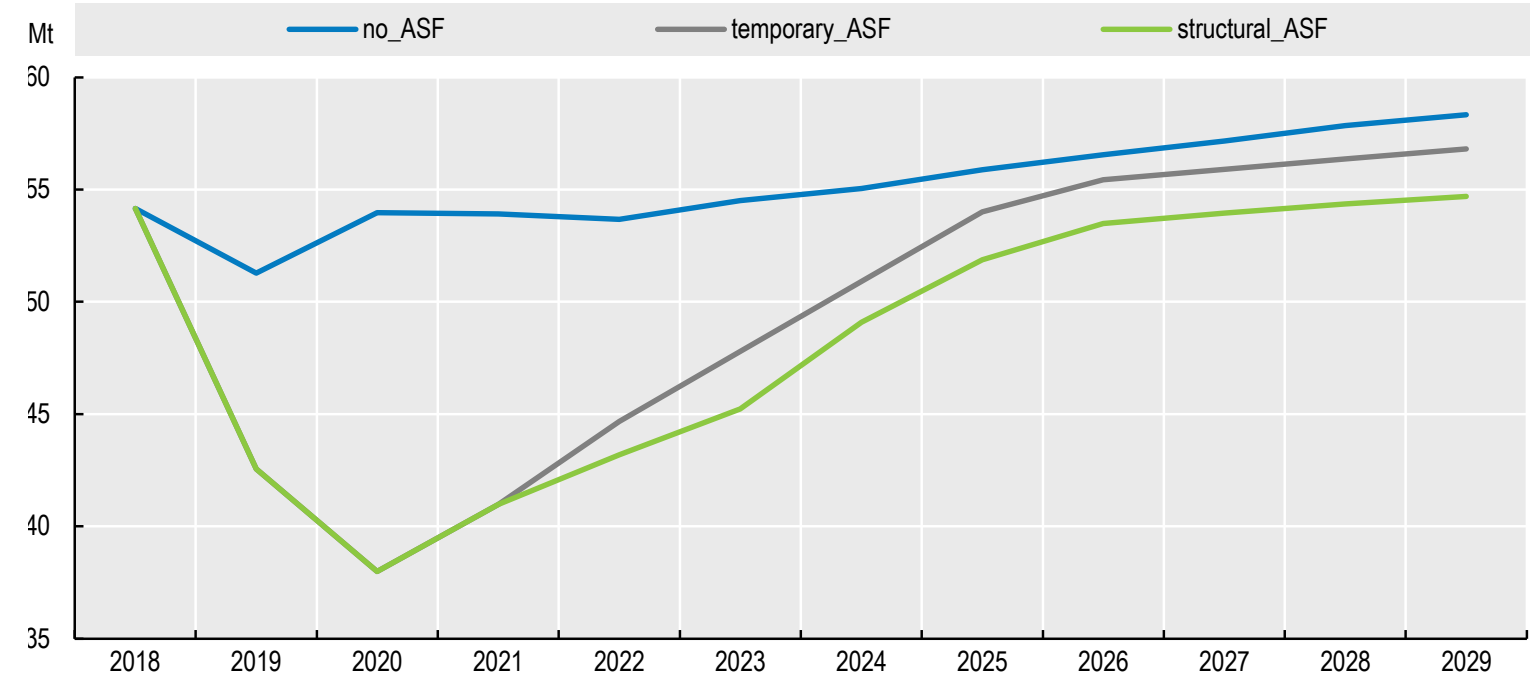

Source: OECD/FAO (2020), "OECD-FAO Agricultural Outlook”, OECD Agriculture statistics (database), http://dx.doi.org/10.1787/agr-outl-data-en.

\section{Low pigmeat production and high prices reduce pigmeat consumption in China}

The large drop in Chinese pigmeat production and the subsequent rise in domestic prices lead to a decline in pigmeat consumption in China, and an increase in consumption of other livestock products, especially in the short term (Figure 3).

In the absence of ASF, pigmeat protein consumption in China was foreseen to average $10.4 \mathrm{~g} /$ person/day or $27.6 \mathrm{~kg} /$ person/year in 2020-21. Under both temporary_ASF and structural_ASF, daily pigmeat protein consumption per capita is projected to be $1.7 \mathrm{~g}$ below no_ASF levels in the short term. Consumption of eggs, poultry, fish and ruminant meats, however, increases as these products become relatively more affordable or simply more available. ${ }^{7}$ In the short term, daily per capita protein consumption of these products is projected to be $0.6 \mathrm{~g}, 0.3 \mathrm{~g}, 0.2 \mathrm{~g}$ and $0.1 \mathrm{~g}$ above no_ASF levels, respectively, under both scenarios.

As Chinese pigmeat production gradually recovers and prices fall, pigmeat consumption is expected to start increasing again. Under temporary_ASF, daily pigmeat protein consumption per capita is projected to recover relatively fast and remain only $0.2 \mathrm{~g}$ below no_ASF level by the end of the projection period. Under structural_ASF, pigmeat consumption is expected to recover more slowly and remain $0.7 \mathrm{~g}$ below no_ASF level in the medium term as consumers continue to choose other livestock products over pigmeat. Eggs, poultry and fish protein consumption, on the other hand, are expected to remain $0.6 \mathrm{~g}$ above no_ASF levels under structural_ASF $\left(+0.2 \mathrm{~g}\right.$ for eggs, $+0.3 \mathrm{~g}$ for poultry and $+0.1 \mathrm{~g}$ for fish). ${ }^{8}$ Such a structural change in Chinese diets could have positive effects on environmental outcomes as poultry and fish production have a lower environmental footprint than does pigmeat production.

\footnotetext{
${ }^{7}$ In the short term, the increase in ruminant meatsconsumption is driven by price elasticities.

8 The change in ruminant meats protein consumption is below $0.05 \mathrm{~g}$, as its overall contribution to animal protein consumption in China is only around $10 \%$.
} 


\section{Figure 3. Pigmeat consumption falls, benefiting other livestock products}

Pigmeat, eggs, poultry, fish and ruminant meats protein consumption in China under temporary_ASF and structural_ASF, absolute change to no_ASF scenario

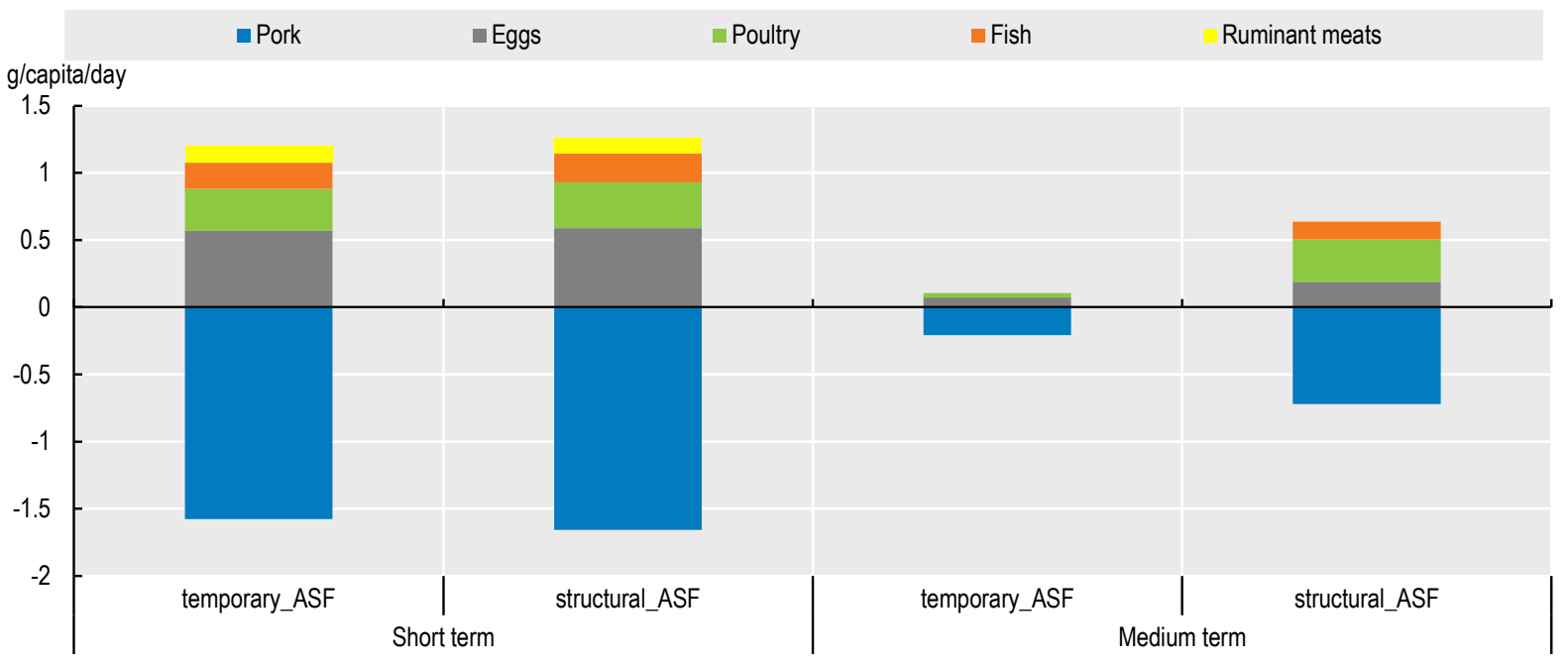

Note: Ruminant meats includes beef and veal and sheep meat.

Source: OECD/FAO (2020), "OECD-FAO Agricultural Outlook", OECD Agriculture statistics (database),

http://dx.doi.org/10.1787/agr-outl-data-en.

\section{Low pigmeat production and high domestic prices spur Chinese imports, creating short- term opportunities for pigmeat exporters}

The drop in pigmeat production and subsequent rise in domestic prices lead to a strong increase in Chinese import demand, especially in the short term (Figure 4).

The ASF outbreak leads to an increase in Chinese pigmeat imports, which are projected to be $2.6 \mathrm{Mt}$ above no_ASF level in the short term under both temporary_ASF and structural_ASF. As Chinese pigmeat production recovers, pigmeat imports are expected to slow down. Under temporary_ASF, such imports are projected to remain only $0.5 \mathrm{Mt}$ above no_ASF level by the end of the projection period. Under structural_ASF, Chinese pigmeat imports will decline further, and almost return to no_ASF levels in the medium term, as some of the demand for pigmeat will be permanently replaced by other livestock products. $^{9}$

\footnotetext{
${ }^{9}$ An important share of Chinese import demand for pigmeat is for specific cuts for which prices on international markets are low. Import demand for these cuts is expected to remain stable over the medium term and thus to account for the majority of China's pigmeat imports.
} 


\section{Figure 4. Production drop causes a short-term rise in Chinese pigmeat imports}

Chinese pigmeat imports under temporary_ASF and structural_ASF, absolute change to no_ASF scenario

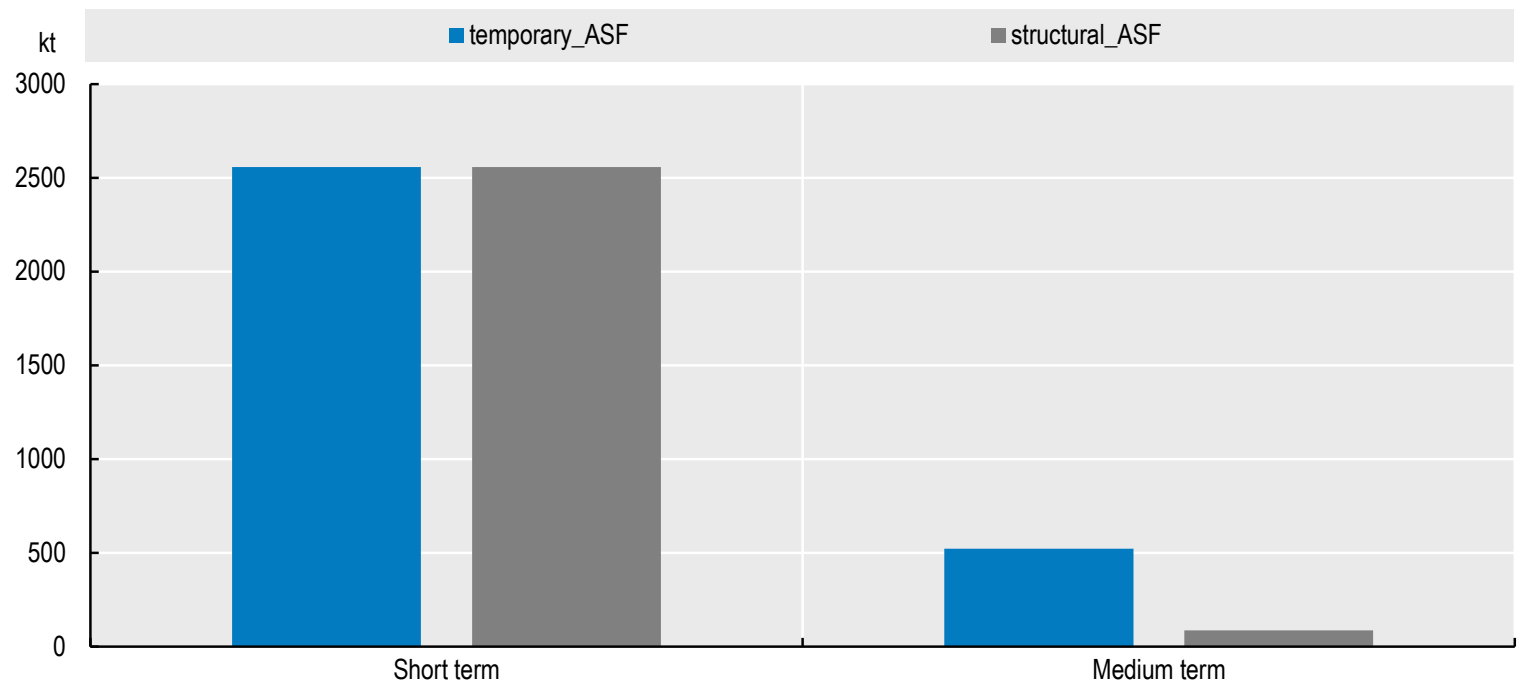

Source: OECD/FAO (2020), "OECD-FAO Agricultural Outlook", OECD Agriculture statistics (database), http://dx.doi.org/10.1787/agr-outl-data-en.

The drop in Chinese pigmeat production due to the ASF outbreak creates temporary export opportunities for large pigmeat exporters. In the short term, the European Union, the United-States, Brazil, and Canada benefit from a significant increase in their pigmeat exports, as confirmed by preliminary trade data for 2020 (United Nations, 2021[10]). Pigmeat exports by these regions and countries are projected to be $886 \mathrm{kt}$, 458 kt, 395 kt and 129 kt above no_ASF levels, respectively, under temporary_ASF and structural_ASF (Figure 5). However, as China restores its pigmeat production, pigmeat exports from these regions and countries are expected to decline and return to levels close to the no_ASF scenario in the medium term.

These trade projections are subject to uncertainties regarding the spread of ASF to other countries and the disruptions caused by COVID-19. If ASF continues to spread in the European Union, for example, their pigmeat exports would be lower than anticipated while exports from other countries could increase further. The import restrictions imposed by China either on countries affected by ASF (e.g. some EU countries) or as a result of the pandemic are also disrupting pigmeat trade and could result in lower Chinese pigmeat imports than currently anticipated.

After being detected in China in 2018, ASF spread to other countries in Asia (e.g. Viet Nam) (Box 1). These countries cannot currently supply the Chinese market. The speed of recovery of other Asian countries from ASF will also affect the volume and direction of pigmeat trade over the coming years. 
Figure 5. ASF outbreak in China creates temporary export opportunities for the European Union, the United States, Brazil, and Canada

Pigmeat exports under temporary_ASF and structural_ASF, absolute change to no_ASF scenario

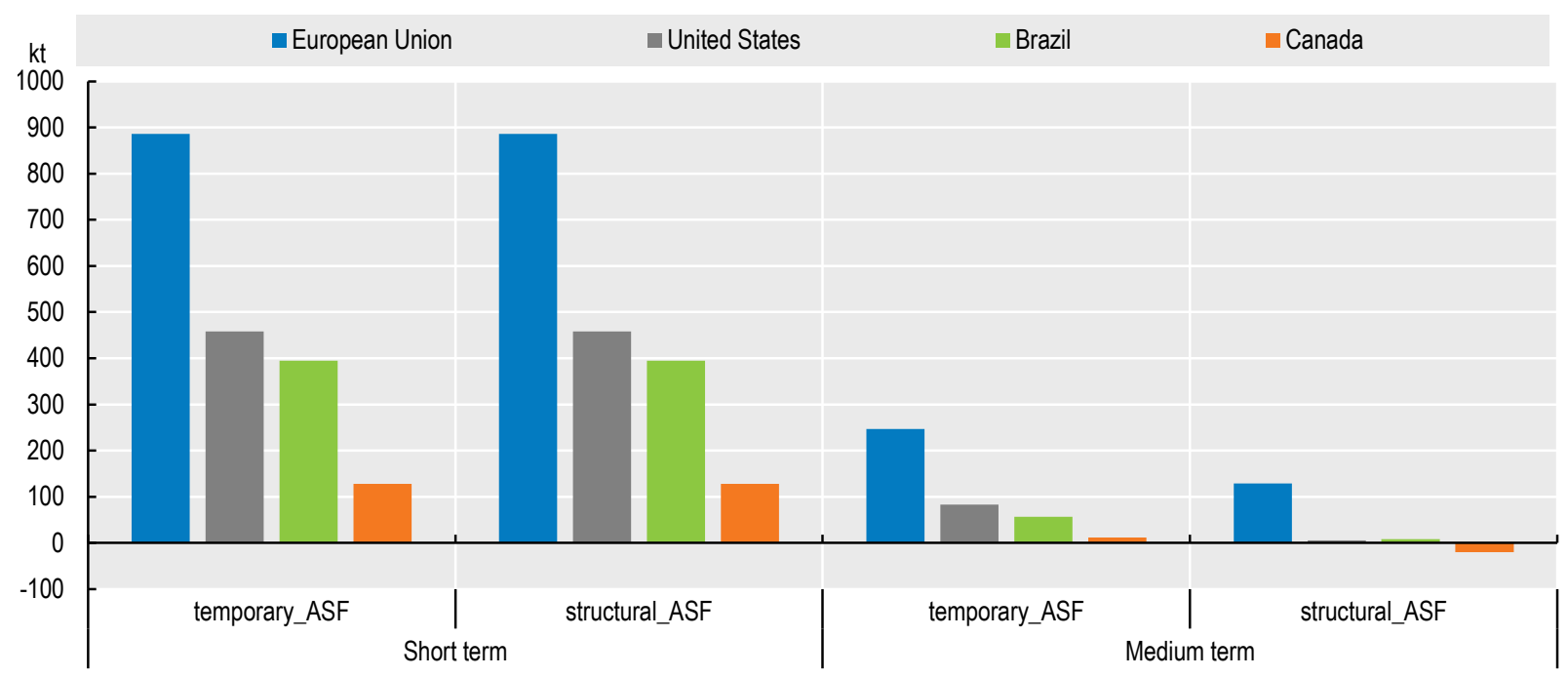

Source: OECD/FAO (2020), "OECD-FAO Agricultural Outlook", OECD Agriculture statistics (database),

http://dx.doi.org/10.1787/agr-outl-data-en.

High Chinese import demand causes an increase in international pigmeat prices

The strong effect of Chinese import demand on international markets leads to a short-term increase in international pigmeat prices (Figure 6). In the short term, international prices increase by almost $9 \%$ above no_ASF level under both temporary_ASF and structural_ASF. These high prices increase the profitability of the pigmeat sector and create incentives to expand production (for those not affected by ASF) or to start restocking as soon as possible (for others).

As Chinese pigmeat production begins to recover and import demand slows, international pigmeat prices are expected to decline. Under temporary_ASF, international prices will almost go back to no_ASF level by the end of the projection period. Under structural_ASF, international pigmeat prices will decline further and are projected to be $3 \%$ below no_ASF level in the medium term, due to a slower growth in Chinese import demand.

High pigmeat prices on international markets are not currently observed because disruptions caused by ASF and COVID-19 are pushing prices in opposite directions. The drop in income resulting from the pandemic is reducing global demand for high-value animal products such as pigmeat. As it takes time for supply to adjust and match lower consumer demand, this results in a relative oversupply in the short term, causing prices to decline (OECD, 2020[11]).

Because of the countervailing effects of ASF and COVID-19, it is not clear what the net impact of these two shocks is on pigmeat prices. In the short term, the impacts of ASF and COVID on prices are expected to be of similar magnitude, thus their total effect might not be very different from a situation without these shocks. In the medium term, COVID will have a greater impact on prices as its macroeconomic effects are expected to be long lasting, while a quicker recovery is projected for ASF. 


\section{Figure 6. ASF supports global pigmeat prices}

Atlantic pigmeat prices under temporary_ASF and structural_ASF, \% change to no_ASF scenario

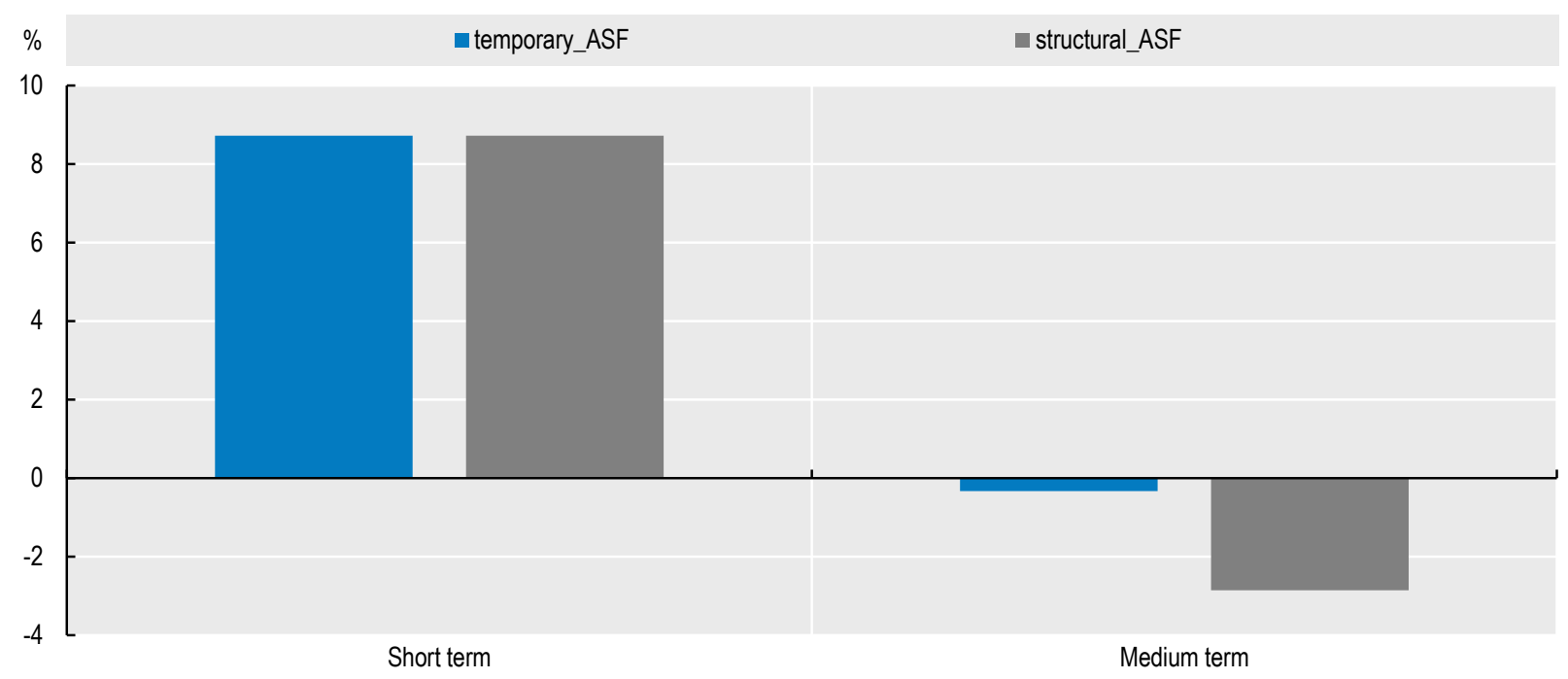

Note: Atlantic pigmeat prices: frozen pigmeat, export unit value in Brazil, product weight.

Source: OECD/FAO (2020), "OECD-FAO Agricultural Outlook", OECD Agriculture statistics (database),

http://dx.doi.org/10.1787/agr-outl-data-en.

\section{Lower hog population in China reduces feed use and soybean and cereals imports}

The impact of ASF on pigmeat production spills over into the feed market. First, the drop in Chinese hog population reduces feed use, especially in the short term (Figure 7). In the short term, under both temporary_ASF and structural_ASF, total feed use in China is projected to be almost 50 Mt below no_ASF levels. Maize and protein meal, which are the main components of hog rations, are projected to be $16 \mathrm{Mt}$ and $12 \mathrm{Mt}$ below no_ASF levels, respectively.

As China rebuilds its domestic pigmeat supply, feed use is projected to start increasing again, as indicated by recent Chinese purchases of soybean, maize and other feed grains (United Nations, 2021 [10]). Under temporary_ASF, feed use will remain less than $4 \mathrm{Mt}$ below no_ASF level by the end of the projection period. Under structural_ASF, feed use will recover more slowly and remain almost $8 \mathrm{Mt}$ below no_ASF level in the medium term, as some of the demand for pigmeat will be permanently replaced by demand for less feed intensive livestock products (eggs, poultry, and fish from aquaculture).

Herd rebuilding in China is characterised by a move away from backyard production towards larger, modern production facilities that can ensure biosecurity. These production facilities use compound feed more consistently, which could lead to further intensification in feed use over the medium term. However, these facilities also have better feeding efficiency than the first generation feed-based facilities, enabling a reduction in feed use per unit of livestock product. In this analysis, we assume that these two trends will counterbalance each other, so that total feed use gradually approach no_ASF levels as China rebuilds supply. 


\section{Figure 7. ASF outbreak reduces feed use in China}

Chinese feed use under no_ASF, temporary_ASF and structural_ASF

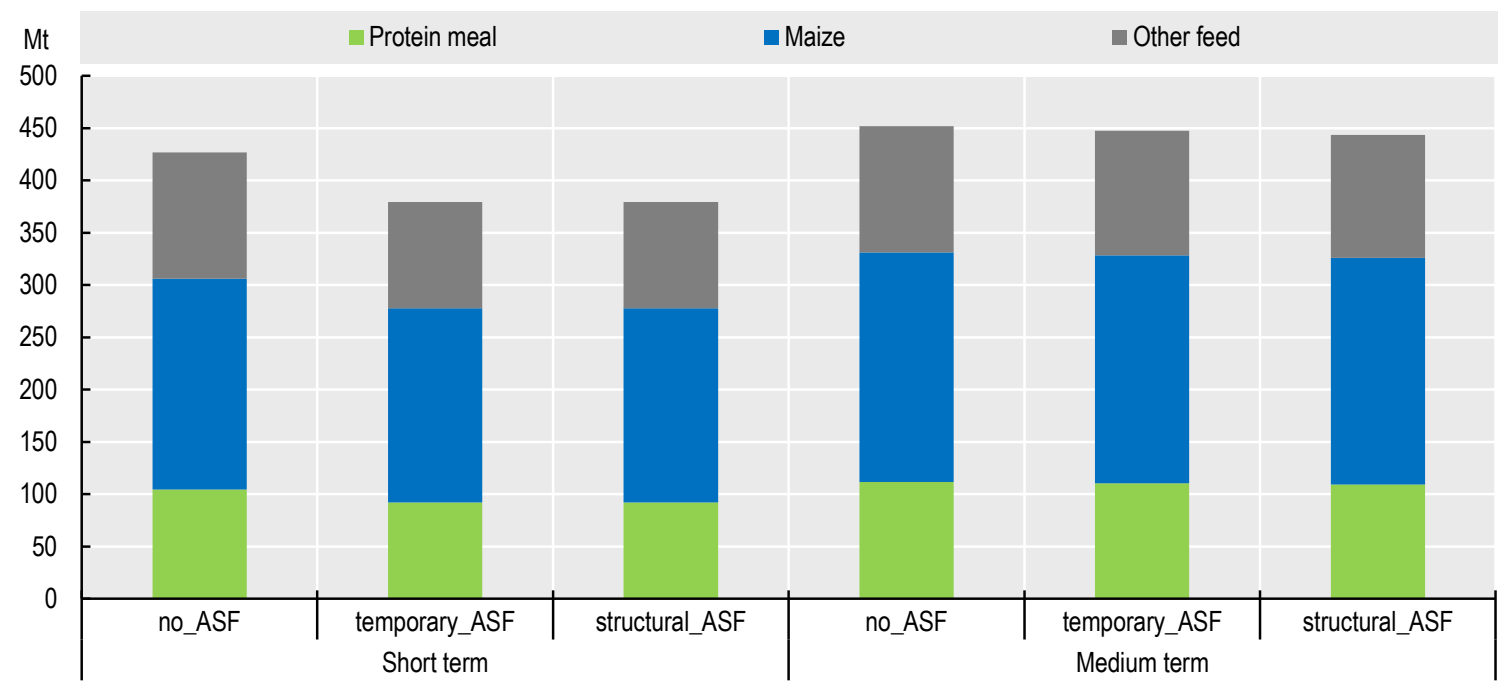

Source: OECD/FAO (2020), "OECD-FAO Agricultural Outlook", OECD Agriculture statistics (database), http://dx.doi.org/10.1787/agr-outl-data-en.

The drop in Chinese hog herds and associated reduction in feed use put downward pressure on Chinese imports of soybean and cereal products that are mainly used as feed. In the short term, Chinese imports of soybean, maize, and other coarse grains (OCG) are projected to be $5.5 \mathrm{Mt}$ below no_ASF levels under both temporary_ASF and structural_ASF (-3 Mt for soybean, - $0.8 \mathrm{Mt}$ for maize and $-1.4 \mathrm{Mt}$ for OCG) (Figure 8). This drop affects mainly the United States and Brazil, the main feed exporters to China. However, the current high Chinese demand for feed on international markets indicates that herd rebuilding has started.

As Chinese pigmeat production gradually recovers, Chinese soybean, maize and OCG imports are projected to start increasing and to remain less than $1 \mathrm{Mt}$ below no_ASF levels in the medium term under temporary_ASF. Under structural_ASF, imports will recover more slowly and remain $1.6 \mathrm{Mt}$ below no_ASF level by the end of the projection period. Maize imports, however, are projected to fully return to no_ASF level as they are less reactive to changes in demand than are soybean and other cereals. Maize imports are mostly determined by tariff rate quotas, which are assumed to be filled by the end of the projection period.

Trade tensions can considerably alter these projections. Since 2018, the trade war between the United States and China has strongly disrupted soybean trade and led to a drop in US soybean exports to China. The implementation of the Phase One trade deal, however, could boost US soybean and maize exports to China in the coming years. ${ }^{10}$ Other tensions are currently disrupting trade in cereals and oilseeds. These include China's current tariffs on Australian barley exports and China's import restrictions on Canadian canola. These restrictions make China's feed imports more expensive, and could lead to a larger drop in cereals and oilseed imports in the short term than that projected in these scenarios.

10 The OECD-FAO Agricultural Outlook 2020-2029 assumes that tariffs between the United States and China will remain at current levels over the projection period, but that other measures, beyond tariffs, will be taken that increase trade between the two countries. 


\section{Figure 8. ASF temporarily reduces Chinese imports of soybean and feed grains}

Chinese imports under temporary_ASF and structural_ASF, absolute change to no_ASF scenario

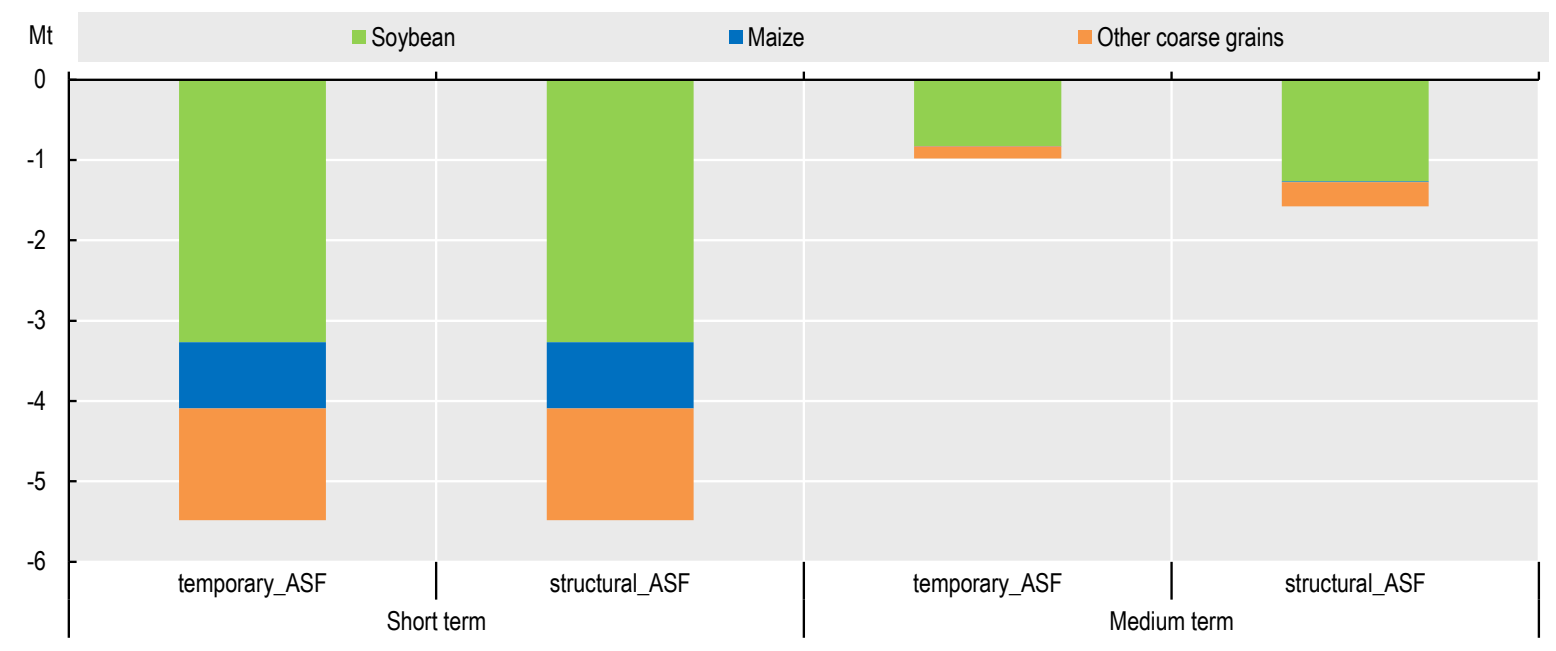

Source: OECD/FAO (2020), "OECD-FAO Agricultural Outlook", OECD Agriculture statistics (database), http://dx.doi.org/10.1787/agr-outl-data-en.

\section{Conclusion}

The ASF outbreak in China is causing a large drop in domestic production, which is creating volatility on global markets for pigmeat and other livestock products, and reverberating through markets for feed. However, given that a quick recovery in Chinese production is anticipated, these effects will likely be temporary.

These effects could nevertheless persist over the medium term depending on whether the production shock induces a change in consumer preferences in China, whereby consumers shift their consumption to other protein sources on a more permanent basis. In this case, the medium term impact of ASF on global markets for feed, and to some extent for livestock products, will be significant. A more permanent $8 \%$ shift in Chinese demand away from pigmeat towards less feed intensive livestock products could reduce global feed use in China by $8 \mathrm{Mt}$ per year in the medium term. 


\section{References}

anses (2021), African swine fever in 11 questions, https://www.anses.fr/en/content/africanswine-fever-11-questions (accessed on 16 February 2021).

European Commission (2021), Animal Disease Information System (ADIS), https://ec.europa.eu/food/animals/animal-diseases/not-system en.

European Food Safety Authority (n.d.), African Swine Fever, https://www.efsa.europa.eu/en/topics/topic/african-swinefever\#: :text=African\%20swine\%20fever\%20is\%20endemic,Russia\%2C\%20Ukraine\%2C \%20and\%20Belarus.\&text=From\%20Russia\%20and\%20Belarus\%2C\%20the\%20disease \%20spread\%20to\%20the\%20European\%20Union. (accessed on 16 February 2021).

FAO (2021), ASF situation in Asia \& Pacific update, http://www.fao.org/ag/againfo/programmes/en/empres/ASF/situation update.html (accessed on 15 April 2021).

FAO (2021), One year on, close to 5 million pigs lost to Asia's swine fever outbreak, http://www.fao.org/news/story/en/item/1204563/icode/.

IMF (2020), WORLD ECONOMIC OUTLOOK: A Long and Difficult Ascent, http://www.imfbookstore.org.

OECD (2020), OECD Economic Outlook, Volume 2020 Issue 2: Preliminary version, OECD Publishing, Paris, https://dx.doi.org/10.1787/39a88ab1-en.

OECD (2020), The impact of COVID-19 on agricultural markets and GHG emissions, http://www.oecd.org/coronavirus/policy-responses/the-impact-of-covid-19-on-agriculturalmarkets-and-ghg-emissions-57e5eb53/.

OECD/FAO (2020), OECD-FAO Agricultural Outlook 2020-2029, OECD Publishing, Paris/Food and Agriculture Organization of the United Nations, Rome, https://dx.doi.org/10.1787/1112c23b-en.

OECD/FAO (2019), OECD-FAO Agricultural Outlook 2019-2028, OECD Publishing, Paris/Food and Agriculture Organization of the United Nations, Rome, https://dx.doi.org/10.1787/agr outlook-2019-en.

pig333.com (2021), , https://www.pig333.com/ (accessed on 15 April 2021).

United Nations (2021), UN Comtrade Database, https://comtrade.un.org/ (accessed on 15 April 2021).

USDA (2020), USDA PS\&D database, https://apps.fas.usda.gov/psdonline/app/index.htm/\#/app/home (accessed on 16 February 2021).

World Organisation for Animal Health (2018), African Swine Fever, https://www.oie.int/en/animal-health-in-the-world/animal-diseases/african-swine-fever/ (accessed on 16 February 2021). 


\section{OECD FOOD, AGRICULTURE AND FISHERIES PAPERS}

This report was prepared for publication by the OECD Secretariat.

This report, as well as any data and any map included herein, are without prejudice to the status of or sovereignty over any territory, to the delimitation of international frontiers and boundaries and to the name of any territory, city or area.

The statistical data for Israel are supplied by and under the responsibility of the relevant Israeli authorities. The use of such data by the OECD is without prejudice to the status of the Golan Heights, East Jerusalem and Israeli settlements in the West Bank under the terms of international law.

Comments are welcome and can be sent to tad.contact@oecd.org. 